\title{
O PENSAMENTO DE PAULO FREIRE E O ENSINO DE FILOSOFIA
}

\author{
Homero Santos Souza Filho ${ }^{1}$
}

RESUMO: Pretende-se, neste artigo, apresentar a relação entre o pensamento de Paulo Freire, em especial o pensamento desenvolvido na obra Pedagogia da Autonomia, e o Ensino de Filosofia. A intenção aqui é avaliar as possíveis contribuições que a pedagogia de Freire pode proporcionar para a reflexão e prática do ensino da Filosofia. Será verificada assim a compatibilidade entre essa pedagogia e as concepções mais recentes sobre o ensino, ou sobre a didática da Filosofia. Alguns dos "saberes para a prática educativa" propostos por Paulo Freire, como a superação da curiosidade ingênua pela curiosidade epistemológica, o "pensar certo", o "inacabamento" do ser humano, entre outros, além de conceitos como o da "contextualização" são adequados e pertinentes para o ensino da filosofia, alinhando-se assim à concepção de que "ensinar filosofia é ensinar a filosofar", e às funções comumente atribuídas a este ensino, como a formação para a cidadania e o desenvolvimento do pensamento crítico. Dessa forma, a pedagogia freiriana pode ser um importante referente teórico para o pensamento e prática do ensino de filosofia.

Palavras-chave: Educação; Ensino de Filosofia; Paulo Freire

\section{PAULO FREIRE'S THOUGHT AND THE TEACHING OF PHILOSOPHY}

ABSTRACT: We intend, in this work, to establish an approximation between the thought of Paulo Freire, especially that contained in the work Pedagogy of Autonomy, and Teaching of Philosophy. The intention here is to evaluate the possibles contributions that the pedagogy of Freire may provide for the reflection and practice of the teaching of Philosophy. We will thus verify the compatibility between this pedagogy and the most recent conceptions about teaching, or about didactics of Philosophy. Some of the "knowledges for educational practice" proposed by Paulo Freire, such as the overcoming of naive curiosity by epistemological curiosity, "right thinking", the "unfinished" human being, among others, are aligned with the conception that "Teaching philosophy is teach philosophizing, "and the functions commonly attributed to the teaching of philosophy, such as training for citizenship, and the development of critical thinking.

Key words: Education; Teaching Philosophy; Paulo Freire

\section{INTRODUÇÃO}

Apesar de tanto o legado de Paulo Freire quanto o ensino de filosofia estarem recebendo diferentes formas de ataques e rechaços, seja com calúnias, insultos, críticas

\footnotetext{
1 Mestre em Filosofia pela Universidade de São Paulo - USP. Doutorando em Educação pela Universidade de São Paulo - USP. E-mail: homero.filho@usp.br

Programas de Pós-Graduação em Ciências Sociais e Filosofia - UNIOESTE - Rua da Faculdade 645. Toledo - PR. CEP 85.903-000 Email: revistaalamedas@gmail.com
} 
infundadas, seja com mais uma exclusão na educação média e desvalorização na Universidade - como vem acontecendo com a filosofia - ambos permanecem importantes para a defesa e luta por uma sociedade mais democrática e tolerante ${ }^{2}$. Talvez, exatamente por ambos os conteúdos serem fundamentais para o desenvolvimento e preservação de um, por assim dizer, espírito democrático, que setores obscurantistas e retrógrados da sociedade vêm constantemente perpetrando ações ofensivas contra eles.

Não há como negar a importância do pensamento de Paulo Freire para a Educação em geral. São inúmeras as contribuições que a Pedagogia, e Filosofia da Educação, desenvolvidas por ele, podem nos trazer para pensarmos as práticas de ensino de qualquer campo do conhecimento, visto que seu pensamento ainda permanece atual. Lembram-nos, por exemplo, Fernanda Silva de Oliveira e Lúcia Helena A. Leite que "a atualidade do pensamento de Paulo Freire vem sendo afirmada pela multiplicidade de experiências que se processam tendo o seu pensamento como referência, em diferentes áreas do conhecimento, no Brasil e internacionalmente" (OLIVEIRA e LEITE, 2012, p. $53)$.

Dessa forma, este artigo procura analisar como que este fecundo pensamento pedagógico pode consistir, por assim dizer, numa importante "ferramenta" para o caso específico do ensino de filosofia, fornecendo assim consideráveis contribuições para as práticas de ensino desse tipo de conhecimento (a filosofia) na Educação secundária. Pois, apesar de a Filosofia como disciplina ter deixado de ser considerada disciplina obrigatória no Ensino Médio, como constava na Lei $\mathrm{N}^{\circ} 11.684$ de 2008, a atual Lei do Ensino Médio, Lei № 13.415, incluí como obrigatório os estudos e práticas de filosofia, além de educação física, arte, sociologia (BRASIL, LEI No 13.415, Art. 35-A, §2). Mesmo havendo essa perda de relevância da Filosofia enquanto disciplina, ela ainda está presente no Currículo do Ensino Médio, o que nos leva a pensarmos sobre o seu

\footnotetext{
${ }^{2}$ Quanto aos ataques e xingamentos sobre Paulo Freire, esses podem ser vistos nas seguintes reportagem e Coluna do site Uol, lamentavelmente perpetrados pelo atual ocupante da Presidência da República: https://educacao.uol.com.br/noticias/2019/12/18/quem-e-paulo-freire-educador-brasileiro-que-virou-alvode-bolsonaro.htm, e a Coluna de Leonardo Sakamoto https://noticias.uol.com.br/colunas/leonardosakamoto/2019/12/16/bolsonaro-chama-educador-de-burro-para-ocultar-seu-governo-ruim-naeducacao.htm. Já o "ataque" sofrido pela Filosofia na Universidade, também realizado pelo Governo da República, trata-se de uma declaração que sugere a intenção de reduzir investimentos nos cursos de Filosofia e Sociologia, como pode-se constatar na seguinte reportagem https://observatoriog.bol.uol.com.br/noticias/2019/04/filosofia-nao-serve-para-nada-governo-bolsonaroreduzira-investimento-em-cursos-de-filosofia-e-sociologia.
}

Programas de Pós-Graduação em Ciências Sociais e Filosofia - UNIOESTE - Rua da Faculdade 645. Toledo - PR. CEP 85.903-000 Email: revistaalamedas@gmail.com 
ensino, tanto no que diz respeito às didáticas adequadas para o ensino da Filosofia, quanto aos propósitos do seu ensino. Com isso, pretendemos reafirmar a importância da Filosofia como matéria indispensável para os estudos, além de buscar os meios mais propícios para fazê-la cumprir seu papel formador do ser-humano, desenvolvendo nele, por exemplo, o senso crítico e o pensamento autônomo.

Ora, dada a indiscutível relevância, originalidade e perenidade do pensamento de Paulo Freire, certamente este tem muito a nos dizer para que possamos refletir sobre a educação filosófica. Além disso, verificamos haver uma significativa compatibilidade, ou proximidade entre algumas concepções de Paulo Freire com as mais recentes concepções sobre o Ensino de Filosofia. Este texto partirá, entretanto, da análise e comparação entre os propósitos, ou objetivos atribuídos ao ensino de Filosofia no Brasil $^{3}$ com os objetivos da educação concebidos e defendidos por Paulo Freire, e depois analisará se há compatibilidade entre as concepções de Freire e as recentes produções sobre o Ensino da Filosofia.

\section{OS OBJETIVOS DO ENSINO DE FILOSOFIA NO BRASIL E OS DA EDUCAÇÃO DE PAULO FREIRE}

Os objetivos e funções atribuídos à Filosofia e ao seu ensino, com o intuito de justificar sua inserção nas escolas brasileiras, provenientes das políticas-públicas educacionais, expressam certos discursos produzidos por movimentos pedagógicopolíticos. Esses movimentos foram protagonistas na recente trajetória do Ensino de Filosofia no Brasil que resultou na Lei $\mathrm{n}^{\circ} 11684$ de 2008, a qual tornou obrigatória a Filosofia nas escolas brasileiras. É dessa forma então que se estabeleceram determinados discursos sobre quais deveriam ser os objetivos da Filosofia na educação brasileira. Assim, como afirma Elisete M Tomazetti sobre um desses importantes movimentos, os Simpósios Sul-Brasileiro sobre Ensino de Filosofia: "os discursos eram hegemônicos com respeito à importância da aprovação da obrigatoriedade da disciplina no currículo escolar brasileiro, (...) ressaltando sua condição de promover mudanças que

\footnotetext{
3 Será analisada também a compatibilidade entre os objetivos do ensino secundário de filosofia na Argentina com o pensamento de Paulo Freire, mais adiante. 
efetivariam uma formação crítica, ética e cidadã dos jovens alunos" (TOMAZETTI, 2012, p. 89).

Esses discursos, produzidos nos anos de 2000, retomavam em certa medida as justificativas estabelecidas pela LDB 9394/96, sobre a tarefa geral da Educação Média, e na qual devem fazer parte os conhecimentos de Filosofia e Sociologia. Assim, como foi observado também no Parecer CNE/CEB n 38/2006:

\begin{abstract}
Não é demais destacar que, na ótica da LDB, os conhecimentos de Filosofia e Sociologia são justificados como "necessários ao exercício da cidadania" (artigo 36, § 1o, inciso III, da Lei $\mathrm{n}^{\circ}$ 9.394/96). Com os demais componentes da Educação Básica, devem contribuir para uma das finalidades do Ensino Médio, que é a de "aprimoramento comopessoa humana, incluindo a formação ética e o desenvolvimento da autonomia intelectual edo pensamento crítico" (art. 35, inciso II, da LDB). E devem, ainda, mais especialmente, seguir a diretriz de "difusão de valores fundamentais ao interesse social, aos direitos edeveres dos cidadãos, de respeito ao bem comum e à ordem democrática" (art. 27, inciso I, da LDB).
\end{abstract}

O estudo da Filosofia, portanto, tem como objetivos gerais, segundo os documentos oficiais e os discursos produzidos em defesa da Filosofia no Ensino Médio no Brasil, a promoção da cidadania, o "aprimoramento da pessoa humana, a formação ética, o desenvolvimento da autonomia intelectual e do pensamento crítico”. Ora, esses são os objetivos de toda "educação progressista", como é o caso da educação idealizada por Paulo Freire, sobretudo na obra Pedagogia da autonomia. Essa finalidade dos componentes da Educação Básica, e entre eles está a Filosofia, é de certa maneira a mesma defendida por Freire.

A educação visa o "aprimoramento da pessoa humana" para Paulo Freire porque ela se confunde com o processo de humanização, estando assim ligada à vocação ontológica dos seres humanos de se humanizarem, o que significa uma busca constante dos seres humanos por "ser mais" (FREIRE, 2017). Nós seres humanos, segundo Freire, somos seres "inacabados", inconclusos, sempre inventando e reinventado assim a nossa existência por meio da linguagem, da cultura, da comunicação (FREIRE, 2008). É neste caso que ter consciência do nosso "inacabamento", é um saber "fundante" da prática educativa, pois a educação, num sentido amplo, envolve a conscientização do nosso inacabamento, visto que, segundo o educador: 


\begin{abstract}
É na inconclusão do ser, que se sabe como tal, que se funda a educação como processo permanente. Mulheres e homens se tornaram educáveis na medida em que se reconheceram inacabados. Não foi a educação que fez mulheres e homens educáveis, mas a consciência de sua inconclusão é que gerou sua educabilidade. É também na inconclusão de que nos tornamos conscientes e que nos inserta no movimento permanente de procura que se alicerça a esperança (FREIRE, 2008, p. 58).
\end{abstract}

Desse modo, por fundar-se na "inconclusão" dos seres humanos e ser o processo de tomada de consciência dela, podemos observar aí a educação como o "aprimoramento da pessoa humana", da consciência da invenção da existência num movimento permanente que caracteriza nosso inacabamento. É neste movimento que se realizam todas as invenções humanas, que se produz os conhecimentos e a cultura, constituindo assim a educação. Nas palavras de Freire: "especificamente humana a educação é gnosiológica, é diretiva, por isso política, é artística e moral, serve-se de meios, de técnicas, envolve frustrações, medos, desejos" (Ibidem, p. 70).

Pela perspectiva freiriana, podemos afirmar ainda que a educação visa o "aprimoramento da pessoa humana", por exemplo, quando Freire exige como um dos saberes necessários à prática educativa "o reconhecimento e assunção da identidade cultural" por parte do educando, e que deve ser promovido então pelo educador. Pois, segundo o autor: "uma das tarefas mais importantes da prática educativo-crítica é propiciar as condições em que os educandos em suas relações uns com os outros e todos com o professor ou a professora ensaiam a experiência profunda de assumir-se" (Ibidem, p. 41). Essa assunção do sujeito deve ser de maneira plena, pois ele deve "assumir-se como ser social e histórico, como ser pensante, comunicante, transformador, criador, realizador de sonhos, capaz de ter raiva porque capaz de amar" (Ibidem, p. 41).

A consciência do nosso inacabamento é o que exige, por sua vez, a nossa formação ética, tanto para os educadores quanto para os educandos. Pois, segundo Freire, essa consciência da nossa "inconclusão" nos fez seres responsáveis, daí o estado de "eticidade" da nossa presença no mundo, e importa a nossa formação ética porque podemos infringir essa "eticidade". O mundo que construímos e humanizamos, segundo Freire, impõe a nós uma educação ética: 
O mundo da cultura que se alonga em mundo da história é um mundo de liberdade, de opção, de decisão, mundo de possibilidade em que a decência pode ser negada, a liberdade ofendida e recusada. Por isso mesmo a capacitação de mulheres e de homens em torno de saberes instrumentais jamais pode prescindir de sua formação ética (FREIRE, 2008, p. 56).

É por essa razão que educar, para Freire, é "substantivamente formar", e esse "caráter formador" da educação é o que há de fundamentalmente humano nela, visto que, segundo o autor: "se se respeita a natureza do ser humano, o ensino dos conteúdos não pode dar-se alheio à formação moral do educando"(Ibidem, p. 33).

Já o "desenvolvimento da autonomia intelectual e do pensamento crítico", esses são as finalidades da educação "democrática, libertária, e progressista" de Paulo Freire que, talvez, mais a caracteriza e que faz dessa educação uma oposição à educação tradicional "bancária" e desumanizadora. A autonomia do educando é certamente uma das principais preocupações freirianas. Não por acaso, o autor postula como um primeiro saber necessário à formação docente o de que "ensinar não é transferir conhecimento, mas criar as possibilidades para a sua própria produção ou a sua construção" (FREIRE, 2008, p. 47). Ensinar aqui é, portanto, não só o abandono como a superação da concepção "bancária" da educação, denunciada por Freire na Pedagogia do oprimido, e a qual entende a educação como "o ato de depositar, de transferir, de transmitir valores e conhecimentos" (Idem, 2017, p. 82).

$\mathrm{Na}$ educação progressista, por sua vez, educador e educandos constroem o conhecimento a partir dos saberes dos educandos (o "saber de pura experiência feito"), do reconhecimento, sobretudo por parte do educador, de que ambos, educador e educandos, ensinam e aprendem. Essa educação deve se realizar ainda numa relação horizontal e por meio do diálogo. A autonomia do educando e o desenvolvimento do seu pensamento crítico são as condições necessárias para a efetivação da aprendizagem, e essas condições provém ainda da consciência de que um verdadeiro processo educacional, horizontal e, portanto, democrático, não deve se reduzir a uma simples "transferência de conhecimentos". O educando precisa estar consciente disso para o seu aprendizado crítico e autônomo:

Faz parte das condições em que aprender criticamente é possível a pressuposição por parte dos educandos de que o educador já teve ou continua tendo experiência da produção de certos saberes e que estes não podem a 
eles, os educandos, ser simplesmente transferidos. Pelo contrário, nas condições de verdadeira aprendizagem os educandos vão se transformando em reais sujeitos da construção e da reconstrução do saber ensinado, ao lado do educador, igualmente sujeito do processo (FREIRE, 2008, p. 26).

O desenvolvimento do pensamento crítico, para Paulo Freire, consiste num processo, não de ruptura, mas de superação de uma condição nossa de "curiosidade ingênua", caracterizada pelo senso comum que é o saber de "pura experiência feito", para uma condição de "curiosidade epistemológica". Na perspectiva freiriana, a curiosidade é uma característica da natureza humana e está ligada a nossa consciência de que somos "inacabados", o que nos conduz a um movimento permanente de busca (FREIRE, 2008). É por essa razão que numa educação progressista e humanística o professor deve estimular essa curiosidade inata por meio do diálogo, de perguntas e "reflexão crítica sobre a própria pergunta", visto que, segundo Freire: "o fundamental é que professor e alunos saibam que a postura deles (...) é dialógica, aberta, curiosa, indagadora e não apassivada, enquanto fala ou enquanto ouve"(Ibidem, p. 86). O que significa que professor e alunos se assumam epistemologicamente curiosos (Ibidem). É nesse sentido que, por assim dizer, o trabalho do professor deve se debruçar fundamentalmente sobre a curiosidade do aluno, exercitá-la ${ }^{4}$, pois, como enfatiza Freire “é preciso, indispensável mesmo, que o professor se ache 'repousado' no saber de que a pedra fundamental é a curiosidade do ser humano"(Ibidem, p. 86). Pois, continua o autor "é ela que me faz perguntar, conhecer, atuar, mais perguntar, re-conhecer" (Ibidem, p. 86):

A "curiosidade epistemológica", na perspectiva de Freire, é o desdobramento da "curiosidade ingênua", que seria a condição primeira da curiosidade humana, mas que, “criticizando-se”, isto é, aproximando-se cada vez mais metódica e rigorosamente do objeto cognoscível, torna-se curiosidade epistemológica (Ibidem, p. 31). Essa curiosidade, portanto, é a dos "cientistas e filósofos", pois é a mesma dos camponeses, segundo o relato do autor, mas que se abre mais ou menos espantada diante dos "nãoeus", curiosidade com que aqueles "admiram o mundo", e assim, segundo o Freire

\footnotetext{
${ }^{4}$ Segundo Paulo Freire (2008, p. 87): "O exercício da curiosidade a faz mais criticamente curiosa, mais metodicamente 'perseguidora' do seu objeto. Quanto mais a curiosidade espontânea se intensifica, mas, sobretudo, se 'rigoriza', tanto mais epistemológica ela vai se tornando". 
(Ibidem, p. 31): “os cientistas e os filósofos superam (...) a ingenuidade da curiosidade do camponês e se tornam epistemologicamente curiosos".

Pode-se inferir assim que os objetivos ou finalidades que se esperam para a Educação Básica e, consequentemente, para a disciplina ou para os estudos da Filosofia, coincidem com os objetivos visados por Paulo Freire na sua concepção de educação progressista, democrática e humanística.

Essa proposta educacional de Freire consiste numa educação que, ao visar àquelas finalidades acima, tem por objetivo a formação científica e filosófica do educando, ocupando-se fundamentalmente com o desenvolvimento da curiosidade epistemológica. Curiosidade que caracteriza uma postura científico-filosófica para com o mundo.

Encontramos aqui um dos motivos que nos leva a afirmar que o pensamento pedagógico de Freire é compatível com o que se espera do ensino da Filosofia. Entendemos ser de considerável contribuição para a reflexão e para a prática do ensino de Filosofia, pois sua pedagogia almeja a formação crítica e plena de todos os sujeitos da educação (educador e educandos), o que se exige então, entre outras formações, como a ética, uma formação científica e filosófica de todos.

Filosofar para Freire, recordemos aqui, é uma das atividades específica de nossa existência; é uma de nossas marcas que nos insere no mundo, pois, de acordo com o educador: "estar no mundo sem fazer história, (...), sem filosofar ${ }^{5}$, sem pontos de vista sobre o mundo, sem fazer ciência, ou teologia, sem assombro em face do mistério, sem aprender, sem ensinar, sem ideias de formação, sem politizar não é possível" (FREIRE, 2008, p. 58).

\section{O ENSINO DE FILOSOFIA NA ARGENTINA E A PEDAGOGIA DE PAULO FREIRE}

Essa compatibilidade entre os objetivos esperados para o ensino de filosofia no Brasil e o pensamento de Paulo Freire, na verdade, transcende as fronteiras brasileiras. Em outros países da América Latina também coincidem esses objetivos e concepções como, por exemplo, ocorre na Argentina. Na verdade, a pedagogia de Freire tornou-se,

\footnotetext{
${ }^{5}$ Grifo nosso.

Programas de Pós-Graduação em Ciências Sociais e Filosofia - UNIOESTE - Rua da Faculdade 645. Toledo - PR. CEP 85.903-000 Email: revistaalamedas@gmail.com
} 
desde o século XX, uma importante referência para o ensino de filosofia na educação secundária argentina.

No pequeno artigo que relata uma pesquisa sobre a matéria de Filosofia nos Liceus polimodais da Argentina "Argentine: laphilosophieenlycéepolymodal, présentation d'unmanuelpourles 15-16 ans",6, as autoras Marie Agostini e Marisa Divenosa apontam a influência que o pensamento pedagógico de Freire ocasionou no ensino de filosofia nesses Liceus argentinos. Com essa pesquisa, as autoras têm por objetivo mostrar como se organiza o ensino de filosofia, quais são seus princípios didáticos e qual é a metodologia proposta para ensinar a filosofia aos adolescentes de 15 a 16 anos. Para tanto, as autoras tomaram como material para a análise os manuais escolares produzidos para os Liceus Polimodais, e escritos por Ivana Costa, professora de filosofia na UBA (Universidade de Buenos Aires), e pela própria autora do artigo Marisa Divenosa. As autoras não deixaram de destacar, no artigo, a importância de Paulo Freire para o ensino de filosofia em toda a América Latina, estando assim relacionado com as novas abordagens neste ensino. De acordo com as autoras: "Desde 1980, os trabalhos de Paulo Freire não cessaram de inspirar novas perspectivas para o ensino de filosofia na América Latina” (2008, p. 1).

Analisando a pedagogia de Paulo Freire, as autoras explicam então que essa, chamada de "pedagogia da libertação", consiste essencialmente em desenvolver o espírito crítico e cívico no educando, por meio da "contextualização" do conhecimento. O que significa dizer que o conhecimento deve estar sujeito às exigências práticas da vida cotidiana, e à compreensão da realidade. Partindo do pressuposto de que, como cada cidadão deve participar da vida política, é essencial que a educação lhe forneça meios para participar dela. Assim, a aprendizagem na escola deve ter, portanto, uma destinação eminentemente concreta, bem como ética e existencial. Essa pedagogia se apresenta assim como pertinente, se não decisiva, para o ensino de filosofia. Pois, de acordo com as autoras:

Os trabalhos de Paulo Freire nos permitem compreender o sentido do ensino de filosofia no Liceu Polimodal. Com efeito, o ensino de "filosofia" não consiste em transmitir uma soma de conhecimentos relativos à história da filosofia. Conforme a pedagogia de Freire, o conhecimento é

\footnotetext{
6 “Argentina: a filosofia no liceu polimodal: apresentação de um manual para os alunos de 15 a 16 anos”. 
“contextualizado", isto é, sujeito à educação. Este ensino se propõe, portanto, abordar os problemas sociais de maneira crítica, por meio de reflexões pelas quais certos conhecimentos, de todo horizonte possível, possam ser expostos e mobilizados.

Vale ressaltar que a influência do pensamento pedagógico de Paulo Freire não se restringiu ao ensino de filosofia na América latina. Pelo contrário, tanto a pedagogia freiriana quanto o consagrado "método Paulo Freire" de alfabetização se fazem presentes em diferentes modalidades e iniciativas na área da educação em todo continente americano.

\section{A “CONTEXTUALIZAÇÃO” NA APRENDIZAGEM DO FILOSOFAR}

Assim como o conceito de "contextualização" de Freire foi fundamental para a compreensão do sentido do ensino de filosofia, e para a elaboração dos manuais de filosofia nos liceus polimodais argentinos, ele também consiste num conceito cuja concepção de educação é importante para se pensar sobre a questão da progressividade da aprendizagem filosófica, isto é, da prática do "fillosofar".

Para refletir sobre a questão da "progressividade da aprendizagem do filosofar", a professora Marie Agostini, no texto "Progressivité de l'apprentissageduphilosopher : lesEssaisde Montaigne” (2011) toma como referência e analisa essa progressão nessa obra clássica de Montaigne. Agostini se apropria assim do conceito de "contextualização" de Paulo Freire, tal como ele o empregou no seu conhecido método de alfabetização para adultos, para elucidar a atitude filosófica em progresso nos Ensaios.

A “contextualização" se expressa na etapa do "debate", ou "discussão" entre os adultos neste método de alfabetização, a qual lhes permitem se inscrever numa aprendizagem de leitura numa perspectiva existencial própria de cada um. Neste caso, eles preenchem, por assim dizer, cada conceito, nesta prática, com um sentido ou significado pessoal. Assim, como observa Agostini, a "contextualização" designa precisamente nesse esforço do educador de tomar o aprendiz, com os seus interesses, como centro e ponto de partida para a educação, construindo a partir daí um caminho em direção a outros saberes. Tal procedimento da contextualização foi, de acordo com Agostini, empregado por Montaigne nele próprio nos Ensaios, pois: “cada ensaio é 
motivado apenas pela curiosidade do próprio Montaigne, inspirado por fatos que podem parecer triviais, e que o são em sua origem, mas que o interpelam, e que ele deseja aprofundar por sua vontade" (AGOSTINI, 2011, p. 2). É aí que reside, segundo a autora, a condição do prazer em filosofar, isto é, na escolha do assunto a investir (Ibidem).

É importante lembrar que o procedimento da "contextualização" não se restringiu ao "método de alfabetização" criado por Paulo Freire. Pelo contrário, a contextualização também é uma prática indispensável, por exemplo, na sua proposta de "educação progressista" que visa à autonomia do educando, tal como ele a desenvolve, posteriormente, na Pedagogia da autonomia (2008). Um dos saberes propostos por Freire, nesta obra, é o de que "ensinar exige respeito aos saberes dos educandos" (Freire, 2008). Isto é, a prática de ensinar não deve estar desvinculada dos saberes e do contexto do educando. A contextualização é, portanto, uma exigência para toda educação que se pretende transformadora. Por isso, Freire sugere: "por que não estabelecer uma 'intimidade' entre os saberes curriculares fundamentais aos alunos e a experiência social que eles têm como indivíduos?" (Ibidem, p. 30). E por que não o fazer de maneira "filosófica", similarmente ao que fez Montaigne nos seus Ensaios?

\section{PRODUÇÕES SOBRE O ENSINO DA FILOSOFIA E O PENSAMENTO DE PAULO FREIRE}

Filosofar para Paulo Freire, como foi visto anteriormente, faz parte do nosso "estar no mundo", isto é, o ato de filosofar é uma das atividades que compõem a nossa condição humana ${ }^{7}$. E essa atividade humana de "fillosofar" vem sendo, por sua vez, desde algumas décadas, o objetivo central de várias produções teóricas sobre o ensino de filosofia, de modo que a questão agora, para muitos, não é mais ensinar filosofia, mas "ensinar a filosofar". Esse deve ser o objetivo buscado pelo professor numa aula de filosofia, especialmente na Educação Média. Numa perspectiva freiriana, poderíamos dizer que, em tais produções, os autores procuraram combater um "ensino bancário da

\footnotetext{
${ }^{7}$ Arriscaríamos dizer que, numa perspectiva freiriana, o ato de filosofar faz mais parte da natureza humana do que a aprendizagem da filosofia, ou de qualquer outro conhecimento, por mera assimilação de conteúdos. 
Filosofia", que caracterizava o ensino de filosofia tradicional, substituindo-o por um ensino mais adequado aos propósitos da Filosofia, e ao público jovem, levando em consideração seu contexto ${ }^{8}$.

Essa reivindicação do "ensino do filosofar" encontra sua fonte de inspiração na própria filosofia com $\mathrm{Kant}^{9}$, para quem não se pode "ensinar filosofia, mas sim a filosofar”. Este enunciado de Kant tornou-se numa das principais referências dessa nova concepção sobre o ensino de filosofia direcionada para o aprendizado e prática do "filosofar". Tal concepção está presente assim em algumas produções recentes sobre o Ensino de Filosofia, ou didática da Filosofia, no Brasil e em outros países.

Uma mudança de concepção sobre o ensino e sobre a didática da Filosofia começou então a ocorrer nas últimas décadas do século $\mathrm{XX}$, por influência daquela passagem de Kant, mas também do que se pode chamar de "pedagogia moderna", como a inspirada no construtivismo.

Alicerçado nas teorias pedagógicas, o ensino de filosofia, como objeto de reflexão, passou a ser pensado com o foco na aprendizagem do aluno. As propostas de ensino, ou de didática da filosofia visavam assim o exercício intelectual, realizado pelo aluno, e que consistiriam na "atividade filosófica", ou no "filosofar". Em outras palavras, o foco dos autores passou a ser o ensino-aprendizagem da prática do “filosofar”, e não mais o ensino voltado para o estudo da história da Filosofia, de modo linear e dividido em "correntes" filosóficas ${ }^{10}$.

De acordo com Joaquim Neves Vicente (1994), o pensamento sobre o ensino de filosofia passou por mudanças de paradigmas durante o século XX. Esses paradigmas se

\footnotetext{
${ }^{8}$ Em consonância a isso, encontramos a concepção marcante do Simpósio Sul-Brasileiro sobre Ensino de Filosofia, mas também de muitos outros agentes em defesa da Filosofia na Educação Básica, que é a de que "Ensinar Filosofia é ensinar a filosofar" (TOMAZETTI, 2012). Este enunciado foi fundamental para o discurso de legitimação da Filosofia na escola. Como destacou Tomazetti (2012, p. 95): "a entrada e a permanência na ordem do discurso que legitimou a importância da Filosofia e de seu retorno às escolas tiveram, então, como corolário, a afirmação (...) - 'ensinar Filosofia é ensinar a filosofar"”.

${ }^{9}$ A concepção do filósofo Immanuel Kant, tornou-se uma referência filosófica frequente nas propostas de um ensino do filosofar. Todos os autores que defendem o ensino-aprendizagem do filosofar retomam, direta ou indiretamente, algumas passagens de Kant sobre o ensino de filosofia, a fim de fundamentar seu ponto de vista sobre o ensino do filosofar. Uma dessas passagens se encontra na Crítica da Razão pura, na qual o autor afirma: "Só é possível aprender a filosofar, ou seja, exercitar o talento da razão, fazendo-a seguir os seus princípios universais em certas tentativas filosóficas já existentes, mas sempre reservando à razão o direito de investigar aqueles princípios até mesmo em suas fontes, confirmando-os ou rejeitandoos" (KANT, 1988, tomo II, p. 239).

${ }^{10} \mathrm{O}$ que chamamos aqui de "ensino ou educação bancária" da filosofia.
} 
sustentavam em diferentes pedagogias, ou em autores do campo da psicologia. Vicente traça um breve panorama dessas mudanças de paradigmas na seguinte passagem:

\begin{abstract}
A centração ${ }^{11}$ da aprendizagem do filosofar nos processos cognitivos e nas destrezas intelectuais, praticamente à margem dos conteúdos, encontra o seu suporte teórico no paradigma cognitivo (J. Piaget, J. Bruner, D. Ausubel, E. Eisner e outros) que veio substituir, nos anos 70, o paradigma condutista(B. Bloom e "Pedagogia por Objetivos"), vigente nos anos 60 e centrado nos comportamentos e resultados esperados, paradigma que havia substituído, por sua vez, o paradigma tradicional (centrado nos conteúdos) (VICENTE, 1994, p. 410).
\end{abstract}

Houve assim uma transição de paradigmas sobre o ensino de filosofia que procuraram superar o paradigma tradicional que era "conteudista", isto é, centrado na história da Filosofia, nos filósofos com seus respectivos conceitos e teorias, que deveriam ser transmitidos aos alunos, e consequentemente "assimilados" por eles.

Essa "mudança de perspectiva" sobre o ensino de filosofia também foi abordada pelo professor e filósofo argentino Alejandro Cerletti em seus trabalhos escritos dedicados em pensar o ensino da filosofia. Num desses escritos, Cerletti (2003) observa que houve mudanças, nos últimos anos, no pensamento sobre o ensino de filosofia, transitando, por assim dizer, de uma concepção tradicional de se pensar a prática do ensino de filosofia, isto é, o modo mais comum de se entender o ensino de filosofia para uma concepção e defesa da perspectiva de "ensinar a filosofar". Ele observa ainda que dessa perspectiva do "ensinar a filosofar", houve, por assim dizer, uma espécie de salto, ou deslocamento para um "ensino filosófico" 12 .

Havia, então, antes dos desdobramentos dessa mudança de perspectiva $^{13}$, segundo Cerletti, um suposto pedagógico trivial na concepção tradicional do ensino de filosofia, uma espécie de "senso comum" constituído em torno do ensinar filosofia, e certamente constituído em outros conhecimentos também. Defendia-se aqui a concepção de que, como resume Cerletti:

\footnotetext{
${ }^{11}$ Palavra do léxico da língua portuguesa de Portugal.

${ }^{12}$ Nas palavras de Cerletti: "Nos últimos dez anos aproximadamente, houve toda uma série de trabalhos relativos à didática da filosofia que avançaram um pouco mais, e hoje poderíamos dizer que é quase ponto pacífico afirmar que o que se trata é, sobretudo, e para muitos o fundamental, 'ensinar a filosofar'. Poderíamos também dizer que se deu uma volta a mais sobre a questão e que devemos falar de um "ensino filosófico"' (CERLETTI, 2003, pp. 64-65). Para ele, essa mudança foi fundamental, merecendo assim ser apreciada, pois consiste numa transformação no modo de pensar a didática da filosofia.

${ }^{13}$ Do "ensino de filosofia" para a perspectiva do "ensinar a filosofar" (CERLETTI, 2003).
} 
(...) há alguém que "sabe" algo e alguém que não o sabe; de alguma maneira aquele que sabe "passa" (basicamente 'explica') ao que não sabe certos "conteúdos" de seu saber e, em seguida, corrobora se essa passagem foi de fato efetivada, isto é, constata que aquele que não sabia "aprendeu". E assim, por etapas graduais e sucessivas, o aluno, com a ajuda de um mestre ou de um professor, passa do não saber ao saber (CERLETTI, 2009, p. 15).

Não é difícil observar que essa concepção tradicional sobre o ensino de filosofia correspondia, em muito, com a concepção geral e também tradicional de educação, a qual Freire vai denominar de "educação bancária", e que vai ser criticada e combatida por ele na Pedagogia do oprimido (2017) ${ }^{14}$. Freire afirma, por exemplo, que "na visão 'bancária' da educação, o 'saber' é uma doação dos que se julgam sábios aos que julgam nada saber” (FREIRE, 2017, p. 81).

Nesta concepção da "educação bancária", segundo Freire, a tônica da educação é a narrativa pela qual o educador "enche" os educandos com os conteúdos de sua narração. Aqui a realidade se apresenta como algo parado, estático, compartimentado e bem-comportado, o que tende a tornar os conteúdos alheios à experiência existencial do educando e, dessa forma, a palavra se esvazia de sua dimensão concreta, transformandose em "verbosidade alienada e alienante". Isto é, a educação se torna, neste caso, um ato de depositar, em que os educandos são os depositários e o educador, o depositante, e ainda perpetua a alienação e a opressão sobre os educandos (Ibidem).

Essa concepção elaborada por Freire consiste, portanto, numa importante referência para a identificação e superação de um "ensino bancário de filosofia", isto é, do ensino de filosofia tradicional que se caracteriza, basicamente, pela prática de depositar "conhecimentos" e informações da história da filosofia aos alunos. Trata-se assim de uma "ferramenta" para que o professor de filosofia, no Brasil, mas também em outros países como foi o exemplo da Argentina, avalie os "danos" dessa prática tradicional de ensino de história da filosofia, e transforme, dessa forma, sua prática pedagógica.

\footnotetext{
${ }^{14} \mathrm{O}$ próprio Cerletti aponta na passagem citada acima, em nota, essa correspondência entre a concepção tradicional de ensino com a "educação bancária". Ele observa que o filósofo Jacques Rancière havia se encarregado de desnaturalizar aquela concepção tradicional de ensino, assim como o fez também Paulo Freire, desde um outro ponto de vista, com a sua caracterização da "concepção bancária da educação" (Cerletti, 2008).
} 
Mas, há também correspondências entre essa mais recente perspectiva do ensino de filosofia, centrada agora no aprendizado do filosofar, com a "educação progressista", ou "problematizadora", concebida por Freire. O pensamento de Freire, até por conta do seu caráter propositivo, consiste também numa importante referência para as práticas críticas e "problematizadoras" dos paradigmas do "ensinar a filosofar", ou do "ensino filosófico", como nos indica a relação, já abordada aqui, entre a "contextualização" e a prática filosófica de Michel Montaigne.

A respeito da diferença entre a "educação bancária" e a educação que consiste numa prática "problematizadora”, podemos destacar que, como escreveu Freire:

\footnotetext{
Enquanto na prática "bancária" da educação, antidialógica por essência, por isto, não comunicativa, o educador deposita no educando o conteúdo programático da educação, que ele mesmo elabora ou elaboraram para ele, na prática problematizadora, dialógica por excelência, este conteúdo, que jamais é "depositado", se organiza e se constitui na visão do mundo dos educandos, em que se encontram seus temas geradores (FREIRE, 2017, p. 142).
}

Este texto irá comparar agora uma das propostas para o ensino de filosofia na educação secundária cujo foco é o ensino-aprendizado do "filosofar" com algumas concepções de Paulo Freire. Trata-se de uma proposta de didática da Filosofia desenvolvida pelo filósofo e didático francês Michel Tozzi, o qual foi considerado um dos primeiros autores a elaborar uma "didática do filosofar".

Partindo do princípio democrático da "fillosofia para todos", Tozzi vem produzindo, desde o final dos anos 80 , inúmeros trabalhos sobre diferentes questões, ou temas relativos ao ensino de filosofia. Um dos temas mais tratados pelo autor foi o da didática da filosofia. Mais precisamente, Tozzi tem se esforçado em pensar e propor procedimentos didáticos que democratizem o aprendizado filosófico, isto é, que possam fazer com que todos os alunos da "escola de massa" sejam iniciados na reflexão filosófica. Esse autor tem se dedicado, assim, em delinear uma didática da filosofia, apresentando diferentes procedimentos, ou exercícios didáticos que funcionem como "ferramentas" (outils) para ajudar os "novos alunos" do ensino secundário, caracterizados por sua heterogeneidade social e cultural, a se iniciarem na reflexão filosófica. Trata-se, portanto, de uma didática que deve ser adequada a esse público 
específico, levando em consideração sua diversidade e, por assim dizer, déficit de formação, mas também sem perder de vista as exigências próprias da reflexão filosófica.

Para atender a essa dupla exigência política e filosófica ${ }^{15}$, Tozzi recorre ao campo da pedagogia e da didática, mais especificamente, às chamadas "ciências da educação", como "referentes teóricos" para a elaboração dos seus procedimentos e exercícios didáticos. $\mathrm{O}$ autor defende e propõe, neste caso, uma articulação entre filosofia e pedagogia ${ }^{16}$, isto é, entre seus "referentes teóricos" extraídos sobretudo das pesquisas sobre psicopedagogia, e sobre didática, e diferentes referências filosóficas como um recurso fundamental para se alcançar o "ensino filosófico para todos" ${ }^{17}$.

Assim, essa proposta didática tem como um dos procedimentos de caráter filosófico a prática da "problematização" de noções, ou questões filosóficas. Isto é, tal didática concebe a "prática problematizadora" como um dos procedimentos indispensáveis que compõem o "fillosofar". Com isso, essa didática elaborada por Tozzi se assenta, resumidamente, em duas proposições. A primeira delas defende que o ensino da filosofia na educação secundária deve ter por finalidade e objeto a "aprendizagem do filosofar" (TOZZI, 1993). A segunda consiste na concepção de que o "filosofar", como processo do pensamento, pode didaticamente se declinar em três operações intelectuais, a saber: conceituar, problematizar e argumentar (Idem, ibidem); operações as quais Tozzi vai chamar de "objetivos-núcleos". Estes podem ser entendidos como competências, ou capacidades que constituem o "filosofar", e que, portanto, o aluno deve desenvolver no processo de ensino e aprendizagem do "filosofar".

Ora, o "filosofar"com os alunos do ensino secundário, na hipótese didática de Michel Tozzi, exige a operação intelectual de "conceituar", a qual tem como uma de suas vias a "abordagem crítica da opinião" do aluno, por meio do questionamento de sua representação espontânea, confrontando-a com seus colegas e professor (TOZZI, 1993). A operação de “conceituar” requer, portanto, o exercício do pensamento crítico

\footnotetext{
15 Denominamos exigência política a de democratização do ensino filosófico, isto é, a de torná-lo acessível ao "novo público" do ensino secundário; e exigência filosófica a que diz respeito às características próprias do pensamento filosófico, como o de superar a opinião.

${ }^{16}$ Além dessa articulação entre filosofia e pedagogia, o ideal de uma educação democrática, no caso de Tozzi o da democratização do ensino de filosofia, já consiste num ponto de proximidade entre Tozzi e Freire. Como se sabe, Paulo Freire foi um educador que sempre pensou e defendeu uma educação e uma escola democrática. O livro Professora sim, tia não (1997) é, talvez, no qual Freire apresenta de maneira mais explícita sua defesa de uma educação democrática.

${ }^{17}$ Para se atingir assim a chamada "educação de massa", que é a nova realidade da Educação no século XX.
} 
do "aprendiz-filósofo", juntamente com as operações de "problematizar uma questão" e "argumentar sobre uma dúvida ou tese". Por fim, ambas as operações visam e constituem o exercício da atividade filosófica (o filosofar), isto é, consistem na elaboração de uma espécie de conhecimento novo e próprio do aluno.

É possível afirmarmos então que a "educação filosófica" de Michel Tozzi é também uma "educação gnosiológica", similar à concebida por Paulo Freire, visto que há um foco na "construção e re-construção" do conhecimento, no caso, do conhecimento de caráter "filosófico" ${ }^{18}$.Da mesma forma, essa educação visa também a "criticidade", com a abordagem crítica sobre a opinião, e questionamento dos preconceitos, além disso visa também uma postura ética e dialógica. Observemos, dessa forma, a seguinte passagem de Tozzi (Idem, 1994, p. 12):

\begin{abstract}
Um treinamento da argumentação para dominar as formas do raciocínio, voltar-se para a dúvida questionando seus preconceitos, fundar racionalmente o que é afirmado, descentrar-se do seu ponto de vista para apreender a lógica interna, e mesmo a parcela de verdade de seu interlocutor, responder com pertinência a uma objeção sólida, não é favorável para o aprendizado de um procedimento filosófico? Lembremos que esses exercícios apenas fazem sentido se finalizados por uma "ética comunicacional": escutar o outro, permitir ser provocado em suas certezas para questionar sua opinião, buscar a verdade com o outro, tentar não vencer, mas convencer (a si primeiramente) 19
\end{abstract}

Não se pode deixar de frisar que essa proximidade que há entre o pensamento de Paulo Freire e as recentes concepções de ensino, ou didática da Filosofia, como a "didática do filosofar" de Michel Tozzi se devem ao fato de ambos se situarem no contexto da "pedagogia moderna", de onde vêm suas inspirações ou influências, isto é, das teorias pedagógicas desenvolvidas no século $\mathrm{XX}$ de bases cognitivistas ou construtivistas que ocasionaram, por assim dizer, uma espécie de revolução no modo de pensar a educação, e assim nas práticas de ensino de praticamente todos os campos do conhecimento.

\footnotetext{
${ }^{18}$ Há uma busca por uma produção filosófica por parte do aluno, nessa "didática do filosofar" proposta por Tozzi, assim como há uma produção de conhecimento almejada na prática educativa proposta por Paulo Freire. Pois, como este escreve na Pedagogia da autonomia: "Ensinar, aprender e pesquisar lidam com esses dois momentos do ciclo gnosiológico: o em que se ensina e se aprende o conhecimento já existente e o em que se trabalha produção do conhecimento ainda não existente" (FREIRE, 2008, p. 28).

${ }^{19}$ Tradução nossa.
} 
No caso do ensino de filosofia, o autor argentino Guillermo Obiols traça essa relação entre as teorias pedagógicas do século XX com o ensino do filosofar ${ }^{20}$. Assim, ao abordar as transformações que essas teorias ocasionaram, ele afirma que:

\begin{abstract}
(...) ao longo do século XX, a partir de figuras como John Dewey ou dos estimuladores da "escola nova", a pedagogia realizou uma crítica das ideias pedagógicas tradicionais que colocavam um estudante passivo que como extremidade de uma cadeia de transmissão deveria incorporar os conhecimentos dos livros e a palavra do professor. De forma complementar, as teorias construtivistas da aprendizagem, de Piaget em diante, enfatizaram que não se aprende vendo, mas perguntando, que a aprendizagem significativa supõe uma assimilação do real e uma reconstrução no sujeito dos conhecimentos anteriores (...). A pedagogia ativa e as teorias construtivistas da aprendizagem transladaram-se às aulas com resultados diversos (OBIOLS, 2002, p. 112).
\end{abstract}

Paulo Freire, por sua vez, parte de pressupostos teóricos e concepções semelhantes, para não dizer as mesmas, das teorias construtivistas, como a de Jean Piaget, além de sua base teórica assentada no marxismo. Num estudo em que compara estes autores, Fernando Becker (BECKER, 2017) observa que para ambos, Freire e Piaget o ser humano se constrói afetiva, cognitiva, moral e socialmente. Na continuidade desse estudo comparativo, Becker confronta suas concepções, revelandonos a proximidade teórica que há entre os autores:

\begin{abstract}
As concepções epistemológicas desses autores têm base interacionista ou construtivista segundo a qual o conhecimento resulta de construções devidas à ação do sujeito, em níveis de progressiva complexidade, em interação com o mundo, a sociedade ou a cultura. Para Piaget, "Toda ênfase é colocada na atividade do próprio sujeito, e penso que sem essa atividade não há possível didática ou pedagogia que transforme significativamente o sujeito" (...); para Freire, "[...] o conhecimento se constitui nas relações homem-mundo, relações de transformação, e se aperfeiçoa na problematização crítica destas relações" (...). Ambos compreendem o sujeito humano como um organismo vivo, personificado num indivíduo que é gerador de ações e decisões, cujo estatuto é irredutível à totalidade social, embora seus limites temporais e espaciais sejam delineados pelo entorno cultural, histórico e social; sob o ponto de vista epistemológico, como sujeito (BECKER, 2017, pp. 10-11).
\end{abstract}

É numa concepção semelhante sobre o sujeito no processo educacional - para não dizer a mesma - que no século XX os autores das propostas de ensino de Filosofia deslocaram o foco de suas respectivas abordagens, como foi o caso de Michel Tozzi,

\footnotetext{
${ }^{20}$ Assim como abordou também Vicente, como podemos observar na citação mais acima. 
defendendo agora não propriamente o ensino da Filosofia, mas o processo de ensinoaprendizado da atividade filosófica, isto é, do filosofar empreendido pelo aluno, focando-se assim no sujeito (o aluno), compreendido como capaz não só de aprender como de "fazer filosofia", ou seja, de "filosofar".

\section{CONSIDERAÇÕES FINAIS}

Este texto procurou, em primeiro lugar, demonstrar o quanto o pensamento de Paulo Freire se aproxima e pode assim vincular-se a certas concepções sobre o ensino de filosofia, isto é, que o pensamento pedagógico e filosófico de Freire está em consonância com as mais recentes concepções de Ensino de Filosofia elaboradas a partir do século passado e cujo foco é o ensino-aprendizado do "filosofar". Buscou-se, também, mostrar como que as finalidades da educação para Freire correspondem aos objetivos, ou finalidades que se esperam do ensino da Filosofia nas escolas brasileiras e latino-americanas.

Dessa forma, o intuito deste estudo comparativo foi também ressaltar as possíveis contribuições que a pedagogia de Paulo Freire pode trazer para a reflexão e para a prática do ensino da Filosofia. Entendemos que Freire se apresenta como um autor indispensável para o professor de Filosofia brasileiro, devido à heterogeneidade e às carências dos alunos, nas diferentes regiões do nosso país. Não há dúvida de que, com sua pedagogia progressista, visando à autonomia do educando, o desenvolvimento do pensamento crítico e a ética, Freire é um importante aliado da Filosofia na escola.

Por outro lado, não há dúvida também de que a Filosofia pode - e muito contribuir para se pensar a educação, apresentando-se como, por assim dizer, uma "ferramenta" fundamental para se pensar o ensino, na sua teoria e na sua prática. É com os conhecimentos da Filosofia que, nós educadores, podemos pensar e aperfeiçoar nossa prática de ensino, como afirmou Paulo Freire (1997): “É desvelando o que fazemos desta ou daquela forma, à luz de conhecimento que a ciência e a filosofia oferecem hoje, que nos corrigimos e nos aperfeiçoamos. É a isso que chamo pensar a prática e é pensando a prática que aprendo a pensar e a praticar melhor”.

\section{REFERÊNCIAS BIBLIOGRÁFICAS}

Programas de Pós-Graduação em Ciências Sociais e Filosofia - UNIOESTE - Rua da

Faculdade 645. Toledo - PR. CEP 85.903-000 Email: revistaalamedas@gmail.com 
AGOSTINI, Marie; DIVENOSA, Marisa. Argentine: laphilosophieenlycéepolymodal, présentation d'unmanuelpourles 15-16 ans. Diotime: Revueinternacionale de didactique de laphilosophie, 2008. Disponível em: <www.educrevues.fr/DIOTIME/AffichageDocument.aspx?iddoc=38969>

AGOSTINI, Marie. Progressivité de l'apprentissageduphilosopher : lesEssaisde Montaigne. Diotime: Revueinternacionale de didactique de laphilosophie, 2011. Disponível em: <www.educrevues.fr/DIOTIME/AffichageDocument.aspx?iddoc=39595\&pos=9>

BECKER, Fernando. Paulo Freire e Jean Piaget: teoria e prática. Revista Schème, Vol. 9, 2017. Disponível em: <www.marilia.unesp.br/scheme>

BRASIL. Lei de Diretrizes e Bases da Educação Nacional. Lei número 9394, 20 de dezembro de $1996 . \quad$ Disponível em: <http://portal.mec.gov.br/seesp/arquivos/pdf/lei9394_ldbn1.pdf>

FREIRE, Paulo. Pedagogia da autonomia: saberes necessários à prática educativa. Rio de Janeiro: Paz e Terra, 37 ${ }^{\mathrm{a}}$ Ed, 2008.

Pedagogia do oprimido. Rio de Janeiro: Paz e Terra, 64ª Ed, 2017.

d’Água, 1997.

Professora sim tia não: cartas a quem ousa ensinar. São Paulo: Editora Olho

OBIOLS, Guillermo. Uma introdução ao ensino da filosofia. Ijuí: Editora Unijuí, 2002.

OLIVEIRA, Fernanda S. e LEITE, Lúcia Helena A. A atualidade do pensamento de Paulo Freire e sua contribuição para a educação no Brasil. Revista Paidéia, Belo Horizonte, n. 13, Ano 9, 2012.

TOMAZETTI. Produção discursiva sobre ensino e aprendizagem filosófica. Educar em Revista, Curitiba, Brasil, n. 46, p. 83-98, out./dez. Editora UFPR, 2012.

TOZZI, Michel. Contribution à l'élaboration d'une didactique de l'apprentissage du philosopher.Revue Françaisede Pédagogie, 103, pp. 19-31, 1993. Disponível em: <http://www.persee.fr/doc/rfp_0556-7807_1993_num_103_1_1294>

<www.philotozzi.com>

VICENTE, Joaquim N. Subsídios para uma didáctica da filosofia. Revista Filosófica de Coimbra, $\mathrm{n}^{\mathrm{o}}$ 6, pp. 397-412. 1994. Disponível em: <http://www.saavedrafajardo.org/Archivos/Coimbra/06/Coimbra06-05.pdf> 